Fecha: $15 / 08 / 2021$

Medio: El Mercurio de Valparaíso

Supl.: El Mercurio de Valparaiso

Tipo: Actualidad

Título: El complejo escenario de la UDI en la región de cara a las elecciones parlamentarias
Tiraje:

Lectoría:

Pág. : 3

Cm2: 608,8

Favorabilidad:
70.400

$\square$ No Definida

\title{
El complejo escenario de la UDI en la región de cara a las elecciones parlamentarias
}

POLÍTICA. La confección de una lista competitiva de tres candidatos va cuesta arriba, pues varios posibles nombres no están disponibles e inhabilidad de dos militantes pasa la cuenta. Expertos analizan factor Viña y llaman a hacer nuevos pactos.

Pamela Boltei

ndificilmomento vivela UDI en la Región de Valparaíso. Si bien a nivel nacional los partidos de centro derecha no están pasando por su mejor momento, especialmente después de los resultados de las elecciones de mayo pasado, en la zona la situación tiene ingredientes que han complicado alas autoridades en ejercicio y, loquemáslamentan entresus filas, la elección de futuros diputados en noviembre.

Hoy solo tienen un nombre potencialmente definido: el director ejecutivo de Piensa, Juan Pablo Rodríguez, pues ni Carlos Bannen, ni Macarena Santelices están disponibles para ir a una diputación. Se habla de Jorge Castro o de su esposa, Rossana Ducaseau, einclusode quela diputada María José Hoffmann estaría pidiendoa parientes del extranjeroque postulen acá.

Hace ocho años el panorama era muy distinto. En laselecciones de 2013, el partido logró 4 diputados, con buen respaldo desufragios. Así, Andrea Molina (40.790 votos, $30,8 \%$ ); Arturo Squella (32.570 votos, $26,1 \%)$; Osvaldo Urrutia (38.005 votos, $24,4 \%$ y María José Hoffmann (21.870 votos, $26,7 \%$ ) obtuvieron escaños en el Parlamentoholgadamente. Hoy, ninguno de ellos buscará una plaza en el Congreso, por varios motivos.

En el caso de Squella, se encuentra ligado a Republicanos, al igual que la exalcaldesa de $\mathrm{Ol}$ mué, Macarena Santelices, quien es hoy vocera de la campaña presidencial de José Antonio Kast. Hoffmann no puede ir a la reelección por la nueva ley que impide reelegirse por más de dos periodos y Molina, tas in tentar ser senadora y a pesar de haber obtenidola terceramejor votación en la circunscripción de Valparaíso, no pudo quedarse con lasenaturía. Estohizoque la también figura televisiva se alejara del partido para solo volvera hablar con ellos cuando in-
"Siempre critiquéque laUDI estaba muy vinculada con Viña, lo que la ponía en riesgo y esosucedió: cae la administración y cae laUDI".

Macarena Urenda Exconcejala UDI

"Todas las personas quieren subirse al carroganador; por lo tanto, en momentos como este, es lógico que los candidatos sean escasos".

Marcela Porto Analistay doctora (c) en Cs.Sociales

tentó ser alcaldesa de Viña del Mar en las elecciones de este año, perdiendo ante Macarena Ripamonti(RD).

Justamente esto fue un factor determinante para que Urrutia decidiera no ir a la reelección-sí estaba habilitado-dicen fuentes del partido. El actual diputado dijo a este Diario que se alejaba para "dar espacio a rostros nuevos", peroen lainterna se comenta que el motivo real es por la falta de apoyoene territorio tras la salida de la administración Reginato.

"VIÑADEPENDIENTES" Es que lo que ha ocurridoen Viña del Mar, desde hace un tiempo a la fecha, ha complicadoen muchoalaUDI.El problemade déficit y los cuestionamiento que comenzaron a salir a la luz pública sobre pagos extra y otros hechos relacionados a eventuales delitos al interior de la casa consistorial quitaron respaldo politico a lagestión de Reginato, que hasta 2017 era la "joya de la corona" de la tienda.

Para la exconcejala Macare na Urenda, quien fue también candidata a la Convención Constitucional, es difícil remontar si se sigue haciendo todoigual.

“La UDI no lo está pasando

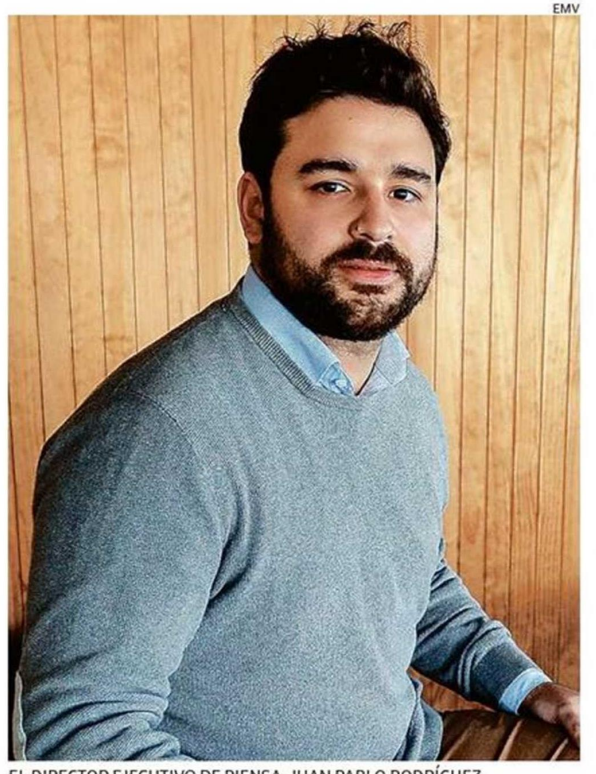

EL DIRECTOR EJECUTIVO DE PIENSA, JUAN PABLO RODRÍGUEZ.

muy bien porque también saliô el fallo absolutamente contundente contra la exalcaldesa (Vir ginia Reginato) y luego viene $\mathrm{l}$ de Mauricio Araneda, loque haceque en el contextoqueseest viviendo ahora, en el caso de UDI, sea más complejo en com paración a otros partidos de de recha o izquierda. Hace tiempo a laUDI regional le hacefalta un autocrítica profunda y redireccionar el partido. Yosiemprecri tiquéque la UDI estaba demasiado vinculada con la administración municipal de Viña, loquel ponía en riesgo y eso sucedió: cae la administración y cae l UDI. Habíamuchaasociaciónde poderes y denombres", dijo.

Marcela Porto, doctora (c) en Ciencias Sociales y académica de laU. Autónoma, asegura que "es una posición dificil la que de be enfrentar la UDI de cara a las elecciones de noviembre, porque personas como Reginato Araneda están vinculados a ca sos que comprometen la probidad administrativa y a cuya información pueden acceder los votantes, que al parecer ya no
2

diputados tiene la UDI en la zona, y los dos no irán a reelección: María José Hoffmann y Osvaldo Urrutia.

permanecen pasivos frente a te tipo de acciones. A esto deb mos sumar el cambio en el esce nario político que dejan las elecciones municipales, el 2016 UDI lideraba 5 comunasen la re gión, para las elecciones del 202 solo se quedó con dos. Esto evidentemente da cuenta de un erosión en el vínculo con la ciudadaníay de unagestión queno logra proyectarse".

Entonces, prosigue, "se construye un clima de opinión fundado, desfavorable para un sector y esto inevitablemente expresará en el voto. Ya lo decía Elisabeth Noelle- Neumann en sufamosa teoría dela espiral de silencio. Todas las personas quieren subirse al carro ganador, por lo tanto en momentos como este, es lógicoquelos candidatos sean escasos".

Frente a ello, señala que "en

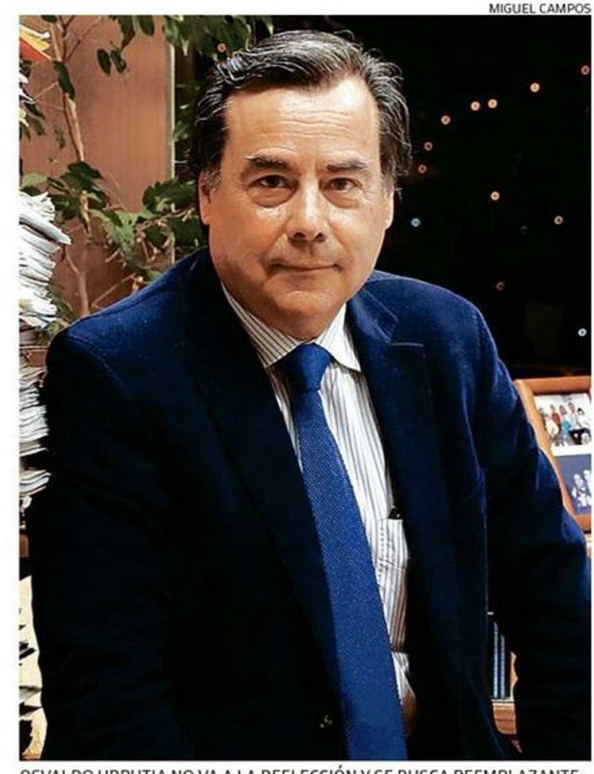

OSVALDO URRUTIA NO VA A LA REELECCIÓN Y SE BUSCA REEMPLAZANTE.

el corto plazo no es mucho lo quepuedehacer" mientras que "para el futuro no queda más que revisar sus prácticas ymirar a las nuevas generaciones".

\section{NUEVOS PACTOS}

or su parte, el analista político de la Universidad Andrés Bello (UNAB), Felipe Vergara, plantea que "el escenario para la UDI está muy complejo", porque "por un lado sus principales cartasen la región han perdidoapoyo tanto por ser partedel gobierno, $\mathrm{co}$ motambién por problemas con la justicia. Además, la irrupción del partido Nacionalista (Kast) también les hace daño y es muy posiblelleven candidatos fuertes

En esa línea, el expertoseñala que "deberán buscar rostros reconocidos nacionalmente, porqueno hay tiempopara nueas caras y que cuenten conel apoyo del candidato de la derecha. No está fácil, es un partido muy dañado y jamón del sándwich entre la derecha dura y la derecha más liberal. Quizá sea una buena opción negociar sus cupos con otros partidos deChivamos y buscar otra región". Para la core y jefa de bancadadelaUDI en el Consejo Regional, María Fernanda González, "es un desafio para la UDI encontrar estos liderazos y potenciar más a futuro. Lo veo como un desafio y una oportunidad", mientras que el diputado y presidente regional del partido, Osvaldo Urrutia, reconoceque "sin duda se trata de un dificil momento para la UDI regional yrequiere que hagamos un profundo análisis introspectivo con el objetode examinarloshechosy circunstancias que nos llevaron a esos resultados. Las personas pasan, los valores y principios nas ideas, otras habrá que ade cuarlas a las exigencias de los tiempos actuales. Por ello es muy importante presentar nue vos rostros yrenovar la forma de hacer política".

Este lunes la UDI regional tendráunareunión dondeabordarán la crisis interna y los nombres para incluiren la lista única de Chile Vamos. 